\title{
No Pain, No Gain?: Therapeutic and Relational Benefits of Subspace in BDSM Contexts
}

\author{
Dulcinea Pitagora \\ Widener University
}

\section{Author Note}

Acknowledgements: Many thanks go to my esteemed colleague, Annalise Ophelian, PsyD, for her collaborative efforts and support in the early development of this research. A prior version of this paper was in press at the Electronic Journal of Human Sexuality, but that iteration was never published due to the discontinuation of the journal. This version has been updated to include the most current literature.

\begin{abstract}
The experiencing of subspace (i.e., an altered psychological, emotional, and/or physiological state) is somewhat common among individuals who identify as masochists and submissives within the Bondage and Domination/Dominance and Submission/Sadism and Masochism (or Sadomasochism) (BDSM; Connolly, 2006) community. Because the BDSM community has been historically vilified due to stereotypes reinforced by negative media exposure and inadequate education (Langdridge, 2006), relatively little is known about the phenomenon of subspace outside of the BDSM community. The occurrence of subspace tends to be a highly sought-after experience in BDSM interactions (known colloquially as "scenes"), therefore it stands to reason that an exploration of the concept could provide clarity regarding the motivations of BDSM practitioners and the benefits they might receive through BDSM interactions. To this end, this article includes a review of social science literature on BDSM interactions with three goals in mind: 1) to discuss the overarching commonalities that exist within the widely varying realm of BDSM interactions and activities; 2) to gain an understanding of the psychological and cognitive shifts (i.e., subspace) that some submissive BDSM practitioners experience during BDSM interactions; and 3) to explore the potential benefits of subspace that may be derived during consensual BDSM interactions. From an analysis of the literature, I conclude that achieving subspace during consensual BDSM interactions might result in a reduction of physical and emotional stress in the submissive partner, as well as heightened intimacy between participants.
\end{abstract}

Keywords: BDSM, subspace, altered state of consciousness, ASC, flow state

Literature on the subject of the alternative sexual practices of bondage, dominance, submission, sadism, and masochism (referred to in this text as BDSM; for a broader explanation of these terms see Connolly, 2006) has historically pathologized BDSM practitioners by focusing on nonconsensual interactions that incorporate elements of sexual sadism or masochism as defined in the Diagnostic and Statistical Manual of Mental Disorders [(DSM); American Psychiatric Association (APA), 2013; Richters et al., 2008]. However, over the past two decades, researchers have increasingly considered BDSM desire and expression as an atypical but healthy variation that over $10 \%$ of the general population 
incorporates into their sexual repertoire (Langdridge \& Barker, 2007; Masters et al., 1995; Richters et al., 2008), and that 30 to $60 \%$ fantasize about (Joyal, 2015; Joyal, Cossette, \& Lapierre, 2015). BDSM practitioners are now understood as a cross-section of society with representation across race, age, education attainment, and socioeconomic status, as well as gender- and sexuality-related identifications (Pitagora, 2013).

While many find it stressful and stigmatizing to identify sexually with a marginalized community (Weinberg, 2006), many BDSM practitioners experience benefits to embracing their sexual orientation or preferences (Williams, 2006). The current shift in clinical attitudes toward BDSM desire and expression may be seen as analogous to the historical classification of homosexuality as a mental illness, and the evolving perspective that same-sex desire represents a healthy form of self-expression (Drescher, 2010; Landridge \& Barker, 2007). Recent studies in the realm of BDSM encourage us to shift our thinking about BDSM as a "recreational leisure" activity (Wismeijer \& van Assen, 2013, p. 2). Research has explored aspects of the practice, such as motivations (Barker, 2007), demographics (Richters et al., 2008), and variations of experience (Weinberg, 2006), though little attention to date has been paid to specific therapeutic benefits of BDSM interactions. Researchers have suggested that BDSM interactions are motivated by a desire to explore and expand sexual experience (Newmahr, 2008), to release feelings of pressure or guilt (Weinberg, 2006), or to achieve the highly sought-after transcendental state of subspace (Rinella, 2013). Though entering subspace is an aspect of BDSM expression that is regarded as desirable by many BDSM practitioners, it has received little attention in the literature (Newmahr, 2008; Rinella, 2013; Williams, 2006). Through an interpretive phenomenological analysis (IPA) of the literature, I will offer a definition of the phenomenon of subspace, and I will explore the varying means of achieving subspace, as well as the associated benefits of this type of altered state of consciousness.

\section{Subspace Defined}

Before understanding what subspace is, it is important to understand the BDSM framework in which it occurs. BDSM is commonly used as an umbrella term, which describes a wide variety of behaviors and sexual self-identifications, including but not limited to the consensual exchange of physical pain states, restraint, psychological games, and assumption of specific roles for the purpose of power exchange (Alison et al., 2001; Kolmes et al., 2006; Janus \& Janus, 1993). The language of BDSM tends to be highly overdetermined, in that it can take on different meanings according to the individuals who are using it. Depending on the perspectives of the participants involved, there may be more of an emphasis on bondage and discipline, which often involves various means of physical restraint with or without the incorporation of pain; on sadomasochism, which typically focuses on the sensation or threat of pain for the intention of sexual pleasure; or on the exchange of dominance and submission, which focuses on a power dynamic that supersedes any other activity (Kolmes et al., 2006; Newmahr, 2010; Nichols, 2014; Weinberg, 2006).

According to BDSM practitioners, subspace might occur in any of the above scenarios, as well in the multitude of roleplay and fetishistic scenes that fit within each of the above categories (Newmahr, 2008, 2010; Nichols, 2014; Rinella, 2013), although it has not 
been explicitly defined in academic literature in terms of psychological and physiological processes. An interpretive phenomenological analysis of social science literature suggests that subspace can be defined as a psychophysical (i.e., reciprocally interactive psychological and physiological) state occurring within the context of a BDSM interaction. This state is often characterized by activation of the sympathetic nervous system, the release of epinephrine and endorphins, and a subsequent period of non-verbal, deep relaxation. This altered state of consciousness may include temporary feelings of depersonalization and derealization (Ludwig, 1966), which are generally experienced as positive and pleasant in the context of a BDSM scene, and may enhance connection and intimacy between partners (Sagarin et al., 2003; Sagarin et al., 2015).

In an article discussing the diversity of behaviors and practices in the realm of sexual sadomasochism, Williams (2006) operationally defines subspace as a phenomenon in which "endorphins produce a powerful natural high" (p. 336). Subspace is a relatively rare but commonly sought-after experience among BDSM participants who identify as masochists, submissives, or bottoms - power role orientations that can be described as passive, receptive, or situated lower in the hierarchical distribution of power (Newmahr, 2008; Nichols, 2014; Rinella, 2013). Nichols (2014) describes subspace as a combination of psychological submissive space and a change in blood flow and body chemistry that produces a feeling similar to flying or floating. Because the participant who identifies as the sadist, dominant, or top in a given scene is generally charged with monitoring and protecting their partner, the bottom in the scene might be better situated for achieving an altered state of consciousness and transcendence (Newmahr, 2010). The participant in the role of masochist, submissive, or bottom may be able to release their own internal monitor in an interaction with a top they trust is capable of holding space for this release of self (Beckmann, 2007). This convergence of negotiation, trust, reciprocal consent, and subsequent internal monitor release provides an entry way to subspace.

In Newmahr's (2008) ethnographic study of sadomasochism, she describes her own experience of subspace during her first BDSM scene as an altered state that felt therapeutic in the same way that deep tissue massage might be; she felt a transition from a state of compulsive constant thought and emotional and intellectual ambivalence to a liberating sense of single-mindedness (Newmahr, 2008). While Baumeister (1997) did not explicitly mention the term subspace in his presentation on sexual masochism at the American Psychological Association convention in 1995, inherent to his definition of masochism was the goal of achieving the same state of mind that Newmahr described as subspace $(2008,2010)$. The author emphasized an escape from self-awareness, compulsive thought, and processing of emotions, which can result in a release of stress and a less burdened identity, characterized by a more focused and single-minded baseline state (Baumeister, 1997). This finding was echoed in research measuring cortisol levels in BDSM bottoms and piercing ritual participants, who engaged in highly physiological stressful activities that resulted in decreased levels of self-reported psychological stress (Sagarin et al., 2015; Lee et al., 2016).

In a collection of essays written by a diverse group of BDSM practitioners and edited by well-published author and sex educator, Tristan Taormino, subspace is described in terms of achieving an altered state of consciousness (ASC, Ludwig, 1966; Rinella, 2013). In 
Ludwig's (1966) article on the relationship between different states of consciousness and the means by which they are altered, ASC is conceptualized as:

... any mental state(s), induced by various physiological, psychological, or pharmacological maneuvers or agents, which can be recognized subjectively by the individual himself (or by an objective observer of the individual) as representing a sufficient deviation in subjective experience or psychological functioning from certain general norms for that individual during alert, waking consciousness (p. 225).

Ludwig (1966) goes on to discuss ways in which ASCs have long been used in a variety of healing practices with goals of meaning-making, emotional catharsis, and rejuvenation; these are the same goals that are important to many BDSM practitioners who seek out the experience of subspace (Baker, 2016; Langdridge, 2007; Yost, 2010). For example, Ludwig (1966) describes certain religious ceremonies, during which individuals attain ASCs in order to gain temporary freedom from their usual identities, or act out sexual conflicts or desires in a socially acceptable context. Through these rituals, the individual's stress and fear are replaced by feelings of security and confidence (Ludwig, 1966). This phenomenon parallels findings in a recent phenomenological study examining the intersection of BDSM and spirituality; one participant in the study reported that her experience of subspace allowed her to transcend ego boundaries and feel an extrasensory connection to others (Baker, 2016).

Ludwig (1966) describes the means by which ASCs are achieved in terms of an interference in an individual's baseline range for: the inflow of stimuli; the outflow of motor processes; cognitive processes; and affect (i.e., expressed or observed emotions).

Interestingly, the only empirical studies to date analyzing altered states of consciousness in BDSM interactions likened subspace and topspace to flow states (Ambler et al., 2017; Lee et al., 2016; Sagarin, 2013; Sagarin et al., 2015), i.e., states of consciousness that allow for intense enjoyment of and deep immersion in life experiences (Csikszentmihalyi, 1990). Csikszentmihalyi (1990) pointed out that these altered states of consciousness could be controlled for optimal experience. It stands to reason that the negotiated and controlled parameters of a BDSM scene would be an ecologically ideal environment for ASCs - such as subspace or topspace- to manifest.

Though academic literature documenting the existence of subspace is sparse, the majority of the literature connects the experience of subspace in BDSM interactions and ASCs (Ambler et al., 2017; Hennen, 2008; Lee et al., 2016; Newmahr, 2010; Sagarin et al., 2015). Newmahr (2010) made an association between the concept of flow states and subspace in describing the intense absorption that occurs in BDSM interactions. An association between subspace and the occurrence of transient hypofrontality was noted in a study exploring altered states of consciousness in extreme rituals; these experiences were compared to the ASCs that sometimes occur in BDSM interactions (Lee et al., 2016).

In the most recent study to date examining the association between BDSM interactions and altered states of consciousness, the authors confirmed that engaging in a submissive or bottom power role orientation was associated with transient hypofrontality, 
resulting in reduced self-reported stress and negative affect, and increased sexual arousal (Ambler et al., 2017). In order to examine an alignment of transient hypofrontality with subspace, the authors collected additional self-reported data describing experiences of subspace; a comparison of these datasets confirmed that the characteristics of transient hypofrontality were consistent with those of subspace (Ambler et al., 2017).

While no research to date has sought to capture the specific experience of subspace and the resulting benefits of achieving this form of ASC, the relationship between ASCs, healing, and social factors were analyzed by Shaara and Strathborn (1992). Given the associations between ASCs and subspace described above, the authors' findings on ASCs can be extended to the analogous experience of subspace. Their study suggested that symbolic action can have a profound effect on psychological processes, and connected trance (a type of ASC) with the healing properties of the trance state. The researchers also questioned the extent to which social flexibility or rigidity support certain ASC behaviors (Shaara \& Strathborn, 1992). This is analogous to the affect social stigma might have on the benefits that can be derived from BDSM practices, in that internalized stigma from rigid socialization might be a barrier to such benefits (Williams, 2006). In an effort provide a more concrete definition of subspace as a type of ASC, the following sections describe the ways BDSM practitioners sometimes enter into subspace, and how subspace might provide a psychological space for healing.

\section{Alternative Pathways to Subspace}

Understanding the context and motivations of BDSM interactions are crucial elements in revealing their meaning to the individuals involved, and any subsequent therapeutic benefits of these interactions. What makes a scene meaningful depends on the set of participants; what activities they collectively choose to participate in; and what specific meanings they have in a given context (Langdridge, 2007; Yost, 2010). The literature reveals two main themes regarding the ways in which individuals might choose to instill meaning to their interactions, including: the administration of pain in order to achieve a transcendent or altered state of consciousness; and an effort toward furthering self-awareness via the forming and enacting of sexual scripts (Alison et al., Nordling, 2001; Santtila et al., 2002). These themes will be elaborated on and explained in the following sections.

\section{Transcendence via Pain}

In the academic literature that associates BDSM experiences with therapeutic transcendence, masochism is often described as a vehicle for attaining the altered state of consciousness that is referred to in the BDSM community as subspace (Baumeister, 1997; Hennen, 2008; Langdridge, 2007; Sagarin, 2013). For example, in Baumeister's (1997) review of empirical findings on masochism, the author suggests that the physical and psychological arousal that BDSM participants derive from consensual painful or humiliating experiences in the context of a BDSM interaction can provide a temporary, beneficial escape from the stress and burdens associated with an individual's daily life and identity. In particular, the analysis contrasts the desire of most people to maintain their self-esteem and 
the control of their environment with the masochist's desire to temporarily relinquish their sense of self and control (Baumeister, 1997; Langdridge, 2007).

Because masochism is antithetical to what most would consider normal operations of the self, it provides an opportunity to obliterate the individual's typical identity during a bounded period of time; subsequently, a focus on an immediately concrete and existential sensory experience replaces perseveration on the stresses and expectations of daily life (Baumeister, 1997). It is suggested that periodic absences from an awareness of self and the pressures associated with identity maintenance can provide relief in the form of a therapeutic reduction of stress. It is important to note that context plays an essential role in the exploration of consensual masochism. That is to say, individuals who seek out this type of interaction do so with specific partners and in the context of a negotiated scene; this generally does not take place in the majority of their interpersonal interactions in daily life.

Langdridge's (2007) analysis of the intersection of masochism with a temporary disintegration of consciousness adds to this premise in emphasizing the sense of agency (i.e., inherent capacity to exert control) within BDSM interactions. In an attempt to explain the eroticism of and potential for transcendence via purposeful, consensual, and contextual pain exchange, Langdridge (2007) offered a perspective on the subject of agency within BDSM interactions through a contrast with Scarry's (1985) assertions regarding agency in her book about torture, The Body in Pain. Scarry (1985) posits that because only fragmentary means of verbalization for the experience of pain are available, the minimal verbal strategies that do exist rely on what she calls the language of agency, characterized by the threat or use of lost or obtained power to convey the experience of pain. Scarry (1985) refers to the exchange of agency in exclusively coercive contexts, but Langdridge (2007) explains that a clear distinction between BDSM and torture can be found in the context and meaning ascribed to the acts. In a consensual BDSM exchange, individuals mutually define the meanings of their interactions, whereas in torture, there may be an explicit meaning to the violent act, but that meaning remains static because of the lack of consent (Langdridge, 2007). Because the context of actual torture prohibits an open verbal exchange, there can be no potential for the kind of expansion of meaning that can exist in BDSM contexts (Langdridge, 2007).

Furthermore, Langdridge (2007) describes consent as a mechanism for generating agency for all parties involved in a BDSM interaction, as opposed to the necessary removal of the victim's agency in the context of non-consensual torture. In taking responsibility for the meaning of a sexual interaction-whether that involves giving consent to temporarily forgo agency, or giving consent to assume an overt position of power within the context of the interaction - the experience is filtered through the intersection of power exchange, and can therefore only be communicated in the collective language of agency (Langdridge, 2007). In doing so, what was previously incommunicable, subjective, and relegated to the internal world of the individual can become externalized, objective, and communicable between the participants in a BDSM interaction (Langdridge, 2007). In other words, the masochist consents to receiving pain, and the sadist/dominant/top consents to administering pain, the reciprocal experience of which is oftentimes coupled with the potential for heightened sexual pleasure via a release of opiate-like endorphins (Hennen, 2008). This sequence of events can provide an entryway to subspace for the bottom in the scene, allowing 
for a temporary respite from the individual's existence, and a psychological space for a state of transcendence (Baumeister, 1997; Hennen, 2008; Langdridge, 2007; Sagarin, 2013).

\section{Self-Awareness via Sexual Scripts}

While masochism focuses on physical sensation as a means of achieving subspace and an escape from the self, some BDSM participants find meaning via a verbal collaboration of ideas that may or may not lead to physical interaction (Taylor \& Ussher, 2001). In this way, sexual scripts - "premeditated sequence[s] of intentional actions" (Santtila et al., 2002, p. 185)—become a vehicle for achieving an altered state of consciousness in order to bring about a heightened awareness of the self (Santtila et al., 2002; Weinberg et al., 1984). In negotiating the specifics of a BDSM interaction, and how certain activities might unfold in a carefully controlled setting bound by agreed upon rules, a context is created in which an individual's psychological characteristics can be emphasized and expressed (Weinberg et al., 1984). In this type of framed fantasy enacted in real time, BDSM participants can behave in ways that may not be socially acceptable or expected in daily life, thereby allowing a release from guilt and social constraints (Weinberg, 2006). This type of interaction can have an impact on the evolution of that individual's identity, including the way they might choose to express themselves sexually (Santtila et al., 2002; Taylor \& Ussher, 2001). One of the benefits in the negotiation of consent that occurs within BDSM interactions is the heightened sense of awareness and introspection participants can gain from discussing the scene (Barker, 2007).

Between 1976 and 1983, a team of researchers interviewed participants from San Francisco and New York BDSM communities regarding the nature of their BDSM practices, and found that many of the participants used the interplay of collaboration and context to determine the meaning of individual sexual acts (Wienberg, et al., 1984), which can be likened to the creation of sexual scripts (Santtila et al., 2002). The study indicated that there are five integral components to constructing most BDSM interactions: 1) establishing power roles (e.g., dominant, submissive); 2) the explicit construction of roleplays, or fantasies to be enacted; 3) the inherent nature of negotiation and consent in these roles and roleplays; 4) the effort participants made to place themselves in a specific sexual context related to the meaning collectively assigned to these roles and roleplays; and 5) that the participants' collective definitions of the activities they performed were interpreted differently according to the specific individuals and the contexts they created (Weinberg et al., 1984).

While the study above presented a blueprint for the creation of BDSM sexual scripts, a study conducted in 2001 revealed four qualitatively distinct themes that can emerge from the creation of BDSM sexual scripts: hypermasculinity; administration and receiving of pain; physical restriction; and psychological humiliation (Alison et al., 2001). Their finding that BDSM activities are often scripted and therefore collaborative suggests that individual sexual repertoires are socially constructed (i.e., scripted, negotiated, and agreed upon) within a specific sexual context (i.e., a BDSM scene collaboration) (Alison et al., 2001; Weinberg et al., 1984). Furthermore, they found that many of the activities were mapped closely on to adjacent sexual script themes according to discrete personal experiences, suggesting that these activities have different meaning depending on the individuals involved and the given 
context of the interaction (Alison et al., 2001). This finding highlights that the participants' preferred BDSM activities evolved through socialization processes and individualized experiences, which often led to new sexual behaviors and the formation of new sexual scripts (Alison et al., 2001). In this way, BDSM interactions that focus on the agreement and enactment of sexual scripts can be said to help further an expansion of an individual's identity.

\section{Conclusion}

Though the concept of subspace is an aspect of BDSM expression that has received little research attention to date, an interpretive phenomenological analysis of the social science literature reveals the phenomenon of subspace to be a sought after altered state of consciousness (Ambler et al.., 2017; Lee et al., 2016; Sagarin, 2013). Through the experience of subspace, an individual might experience a psychophysical state characterized by activation of the sympathetic nervous system, the release of epinephrine and endorphins, and a subsequent period of non-verbal deep relaxation (Hennen, 2008; Williams, 2006). This altered state of consciousness may include a temporary escape from one's identity that can reduce stress and enhance bonding between partners (Sagarin et al., 2003; Sagarin et al., 2015).

Varying themes regarding the ways in which individuals might achieve subspace include masochistic interactions, the experience of which is oftentimes coupled with the potential for heightened sexual pleasure via a release of opiate-like endorphins (Baumeister, 1997; Hennen, 2008; Langdridge, 2007; Sagarin, 2013). A focus on the verbal formation and subsequent enacting of sexual scripts has also been described as a means for accessing subspace, by encouraging a heightened awareness of the self that could in turn further an expansion and evolution of an individual's identity (Baumeister, 1997; Santtila et al., 2002; Weinberg et al., 1984). Though psychologically and physiologically defining a phenomenon that has long been recognized by the BDSM community is valuable in itself, perhaps a higher order value lies in the opportunity it provides for future researchers to investigate the phenomenon of subspace, and fill in conspicuous gaps in the literature on normative BDSM interactions.

The literature indicates that achieving the altered state of consciousness described as subspace during consensual BDSM interactions can directly result in a reduction of physical and psychological stress, and can bring about a feeling of heightened intimacy between partners (Langdridge, 2007; Sagarin et al., 2003; Sagarin et al., 2015). It is interesting to note that sexually charged interactions resulting in feelings of trust, intimacy, and stressrelief are often sought after in all sexual interactions, regardless of whether they incorporate BDSM (Hopkins, 1994; Plante, 2006; Williams, 2006). The implications that surface from this knowledge - that the benefits resulting from the attainment of subspace during BDSM activities (feelings of intimacy and stress-relief) are parallel to those derived from mainstream sexual activities - indicate that BDSM participants share a common goal with those who solely participate in mainstream sexual interactions. It would be enlightening to learn what other common goals and manifestations exist between BDSM and mainstream sexual interactions. 
It is clear that further investigations of subspace are warranted, including both qualitative and quantitative analyses into the nature of BDSM sexual interactions, as well as how these interactions diverge and converge with non-BDSM sexual interactions. As researchers continue to abandon preconceived assumptions that BDSM desire and expression are inherently psychopathological, we open new avenues to understanding these interactions, including: the unique experience of subspace; how and when it is experienced in BDSM interactions; and the therapeutic impact that BDSM interactions - those that include experiences of subspace as well as those that do not-have on participants. Research informed by the growing literature on BDSM subculture, and wary of the historical pathology bias against BDSM exchange, would include larger, more diverse samples, which could produce more accurate and potentially generalizable results in a field that has suffered from lack of available data. As an adjunct to quantitative study of BDSM sexual interactions, continued qualitative inquiry into the phenomenological experiences of BDSM practitioners may enhance our understanding of who engages in these practices, why they choose them, and what they derive from them. This could include a meta-analysis of the existing qualitative data through the lens of interpretive phenomenological analysis, as well as new findings from qualitative and quantitative research informed by this methodology.

The opportunity for research that further elucidates the effects of subspace and BDSM interactions is vast. The literature would be well served to include the results of narrower and more specific studies, such as the therapeutic benefits of topspace (Ambler et al., 2017; Rinella, 2013; Sagarin, 2013, 2015), as well as the range of potential health and wellness factors facilitated by consensual BDSM exchange. Since sexuality and gender are discrete but intertwined constructs (Joseph, Pitagora, Tworecke, \& Roberts, 2013) that tend to be emphasized in subversive BDSM play (McClintock, 1993), BDSM could also be studied more broadly in terms of sexuality and gender, for example, in order to compare similarities and differences in both practice and therapeutic benefits. In the explicit negotiation of power dynamics, and the inherent breakdown of traditional gender and sexual norms, a transcendence is possible, not only for the individuals who practice BDSM, but for all individuals who fall in- or outside of the statistical sexual norm. This line of thinking might dovetail well with a larger scale study, such as analyses of gender identification demographics, and how BDSM interactions might affect an individual's tendency towards gender role stereotyping outside of the BDSM context. It has been suggested that much of what occurs during BDSM interactions is a result of challenges to long-standing gender stereotypes (Hopkins, 1994; Taylor \& Ussher, 2001), therefore a study on the impact this type of play has on the relationship between gender identification and power role preference within the BDSM community could be illuminating, specifically in terms of BDSM participants, as well as the general population.

$\begin{array}{cc}\text { Alison, L., Santtila, P., Sandnabba, K.N., \& } & \text { References } \\ \text { Nordling, N. (2001). Sadomasochistically } & \text { S. A. (2017). Consensual BDSM } \\ \text { oriented behavior: diversity in practice } & \text { facilitates role-specific altered states of } \\ \text { and meaning. Archives of Sexual } & \text { consciousness: A preliminary study. } \\ \text { Behavior, 30(1), 1-12. } & \text { Psychology of Consciousness: Theory, } \\ \text { Ambler, J. K., Lee, E. M., Klement, K. R., } & \text { Research, and Practice, 4(1), 75-91. } \\ \text { Loewald, T., Comber, E. M., \& Hanson, } & \text { American Psychiatric Association. (2013). }\end{array}$


mental disorders (5th ed.). Washington, DC: Author.

Baker, A. C. (2016). Sacred kink: Finding psychological meaning at the intersection of BDSM and spiritual experience. Sexual \& Relationship Therapy, 0(0), 1-14.

Barker, M. (2007). The power of play: healing narratives. In D. Langdridge \& M. Barker (Eds.), Safe, sane, and consensual: Contemporary perspectives on sadomasochism (pp. 197-216). Buffalo, NY: Prometheus Books.

Baumeister, R. F. (1997). The enigmatic appeal of sexual masochism: Why people desire pain, bondage, and humiliation in sex. Journal of Social and Clinical Psychology, 16(2), 133-150.

Beckmann, A. (2007). The 'bodily practices' of consensual 'SM', spirituality and 'transcendence.' In D. Langdridge \& M. Barker (Eds.), Safe, sane, and consensual: contemporary perspectives on sadomasochism (pp. 98-118). Buffalo, NY: Prometheus Books.

Csikszentmihalyi, M. (1990). Flow: The psychology of optimal experience. New York: Harper Perennial.

Drescher, J. (2010). Queer diagnoses: Parallels and contrasts in the history of homosexuality, gender variance, and the Diagnostic and Statistical Manual. Archives of Sexual Behavior, 39(2), 427460.

Hennen, P. (2008). Faeries, bears, and leathermen: Men in community queering the masculine. Chicago, IL: The University of Chicago Press.

Hopkins, P. (1994). Rethinking sadomasochism: Feminism, interpretation, and simulation. Hypatia, 9(1), 116-141.

Janus, S. S. \& Janus, C. L. (1993). The Janus report on sexual behavior. New York, NY: John Wiley.

Joseph, J. A., Pitagora, D., Tworecke, A., \& Roberts, K. E. (2013). Peering into gaps in the Diagnostic and Statistical Manual of Mental Disorders: Student perspectives on gender and informing education. Society for International Education Journal, 7(1), 104-126.

Joyal, C. C. (2015). Defining "normophilic" and "paraphilic" sexual fantasies in a population-based sample: On the importance of considering subgroups. Sexual Medicine, 3(4), 321-330. doi:10.1002/sm2.96
Joyal, C. C., Cossette, A., \& Lapierre, V. (2015).

What exactly is an unusual sexual fantasy? The Journal of Sexual Medicine, 12(2), 328-340. doi:10.1111/jsm.12734

Kolmes, K., Stock, W., \& Moser, C. (2006). Investigating bias in psychotherapy with BDSM clients. Journal of Homosexuality, 50(2-3), 301-324.

Langdridge, D. (2007). Speaking the unspeakable: $\mathrm{S} / \mathrm{M}$ and the eroticization of pain. In D. Langdridge \& M. Barker (Eds.), Safe, sane, and consensual: contemporary perspectives on sadomasochism (pp. 8597). Buffalo, NY: Prometheus Books.

Langdridge, D. \& Barker, M. (2007). Situating sadomasochism. In D. Langdridge \& M. Barker (Eds.), Safe, sane, and consensual: contemporary perspectives on sadomasochism (pp. 3-9). Buffalo, NY: Prometheus Books.

Lee, E. M., Klement, K. R., Ambler, J. K., Loewald, T., Comber, E. M., Hanson, S. A., Pruitt, B., \& Sagarin, B. J. (2016). Altered states of consciousness during an extreme ritual. PLoS ONE, 11(5), 1-22.

Ludwig, A. M. (1966). Altered states of consciousness. Archives of General Psychiatry, 15(3), 225-234.

Masters, W., Johnson, V., \& Kolodny, R. (1995). Human sexuality (2nd ed.). Boston, MA: Little, Brown.

McClintock, A. (1993). Maid to order: Commercial fetishism and gender power. Social Text, 37, 87-116.

Newmahr, S. (2008). Becoming a sadomasochist: Integrating self and other in ethnographic analysis. Journal of Contemporary Ethnography, 37(5), 619-643.

Newmahr, S. (2010). Rethinking kink: Sadomasochism as serious leisure. Qualitative Sociology, 33(3), 313-331.

Nichols, M. (2014). Couples and kinky sexuality: The need for a new therapeutic approach. In: Nelson T., Winawer H. (eds) Critical Topics in Family Therapy. AFTA SpringerBriefs in Family Therapy. Cham, Switzerland: Springer International Publishing AG.

Pitagora, D. (2013) Consent vs. coercion: BDSM interactions highlight a fine but immutable line. New School Psychology Bulletin, 10(1), 27-36.

Richters, J., de Visser, R. O., Rissel, C. E., Grulich, A. E., \& Smith, A. (2008). Bondage and discipline, "sadomasochism" or dominance and submission (BDSM): Data 
from a national survey. The Journal of Sexual Medicine, 5(7), 1660-1668.

Rinella, J. (2013). The dark side. In T. Taormino (Ed.), The ultimate guide to kink: BDSM, role play and the erotic edge. [Kindle DX version, location 4610]. Retrieved from Amazon.com.

Sagarin, B. (2013). Lecture on Hormones, pain, and altered states: A scientific search for the essence of sadomasochism. Personal Collection of B. Sagarin, Northern Illinois University of Dekalb, IL.

Sagarin, B. J., Cutler, B., \& Cutler, N. (2003). Hormonal changes and couple bonding in consensual sadomasochistic activity. Los Angeles: Society for Personality and Social Psychology.

Sagarin, B., J., Lee, E. M., \& Klement, K. R. (2015). Sadomasochism without sex? Exploring the parallels between BDSM and extreme rituals. Journal of Positive Sexuality, 1, 50-55. Available from http://journalofpositivesexuality.org/wpcontent/uploads/2016/05/ParallelsBetween-BDSM-and-Extreme-RitualSagarin-Lee-Klement.pdf

Santtila, P., Sandnabba, K.N., Alison, L., \& Nordling, N. (2002). Investigating the underlying structure in sadomasochistically oriented behavior. Archives of Sexual Behavior, 31(2), 185196.

Scarry, E. (1985). The Body in Pain: The Making and Unmaking of the World. New York, NY: Oxford University Press.

Shaara, L. \& Strathborn, A. (1992). A preliminary analysis of the relationship between altered states of consciousness, healing, and social structure. American Anthropologist, 94(1), 145-160.

Smith, J. A. (1996) Beyond the divide between cognition and discourse: Using interpretative phenomenological analysis in health psychology. Psychology \& Health, 11(2), 261-271.

Taylor, G. W. \& Ussher, J. M. (2001). Making sense of S\&M: A discourse analytic account. Sexualities, 4(3), 293-314.

Weinberg, T. S. (2006). Sadomasochism and the social sciences: A review of the sociological and social psychological literature. Journal of Homosexuality, 50(2-3), 17-40.

Weinberg, M., Williams, C., \& Moser, C. (1984). The social constituents of sadomasochism. Social Problems, 31, 379-389.

Williams, D. J. (2006). "Different (Painfuli) Strokes for Different Folks: A General Overview of Sexual Sadomasochism (SM) and its Diversity." Sexual Addiction \& Compulsivity, The Journal of Treatment \& Prevention. 13(4), 333-346.

Wismeijer, A. \& van Assen, M. (2013). Psychological characteristics of BDSM practitioners. Journal of Sexual Medicine, 10, 1943-1952.

Yost, M. R. (2007). Sexual fantasies of SM practitioners. In D. Langdridge \& $\mathrm{M}$. Barker (Eds.), Safe, sane, and consensual: Contemporary perspectives on sadomasochism (pp. 135-154). Buffalo, NY: Prometheus Books. 